\title{
Retraction
}

\section{Activated macrophages utilize glycolytic ATP to maintain mitochondrial membrane potential and prevent apoptotic cell death}

\author{
A Garedew, SO Henderson and S Moncada \\ Cell Death and Differentiation (2017), 24, 1132; doi:10.1038/cdd.2012.103; published online 24 August 2012
}

Retraction to: Cell Death and Differentiation (2010) 17, 1540-1550; doi:10.1038/cdd.2010.27; published online 26 March 2010

The authors wish to retract the above paper. We have recently identified errors affecting certain panels in Figure 6 , in which data were processed in such a way that the figure panels do not reflect the original data. AG regrets the inappropriate figure manipulations, of which his co-authors were completely unaware. Although we believe that the conclusions reached in this paper are essentially sound, we feel that the most responsible course of action is to retract the paper. We sincerely apologize to the scientific community for any confusion or adverse consequences resulting from the publication of these data. 